\title{
Foto-ensaios de uma investigação sobre a formação docente em artes visuais
}

Photo essays of an investigation on

teacher education in visual arts

Carla Juliana Galvão Alves ${ }^{1}$

Natally Thayna dos Santos ${ }^{2}$

\footnotetext{
1 Docente no Departamento de Arte Visual da Universidade Estadual de Londrina (UEL). Especialista em Cultura e Arte Barroca (UFOP). Mestre e doutora em Educação (UEM). Coordenadora do Projeto de Pesquisa: "A formação do professor de artes visuais em uma perspectiva autobiográfica". Orcid: https://orcid.org/0000-0001-79741490. Lattes: http://lattes.cnpq.br/7627123662548625

E-mail: carlagalvao@uel.br

2 Graduanda em Artes Visuais (UEL), com bolsa de Iniciação científica pela Fundação Araucária, cadastrada no Projeto de Pesquisa: "A formação do professor de artes visuais em uma perspectiva autobiográfica" e com subprojeto intitulado: "Percursos formativos: a cartografia como estratégia de ensino e de pesquisa da/na formação docente". Orcid: https://orcid.org/0000-0002-5476-5039. Lattes:http://lattes.cnpq. $\mathrm{br} / 4340818696881918$

E-mail: natally.thayna@uel.br
} 


\section{Resumo}

Este trabalho apresenta nossas reflexões e percepções a respeito dos processos identitários e de formação do professor de Artes Visuais por meio de foto-ensaios. Insere-se no contexto de um projeto de pesquisa que optou pela Pesquisa Educacional Baseada em Arte (PEBA) como referencial metodológico (HERNÁNDEZ, MARTINS, DIAS) e, no caso deste artigo, põe foco nas contribuições da fotografia como estratégia e instrumento de pesquisa qualitativa (VIADEL, ROLDAN). Esperase contribuir com novas reflexões voltadas para as discussões a respeito de metodologias mais adequadas às questões contemporâneas que surgem nas áreas de arte e educação. O estudo não é e nem pretende ser conclusivo, mas intenta ampliar o diálogo sobre formação do professor de Artes Visuais, de forma colaborativa entre estudantes e professores, pesquisadores e participantes.

\section{Palavras-chave}

Pesquisa Educacional Baseada em Arte; PEBA; Foto-ensaio; cartografia; formação de professores.

\section{Abstract}

This paper presents our reflections and perceptions about the identity and formative processes of the Visual Arts teacher through photo-essays. It is inserted in the context of a research project which opted for Arts-Based Educational Research (ABER) as methodological reference (HERNÁNDEZ, MARTINS, DIAS) focusing on the contributions of photography as a research strategy and qualitative instrument (VIADEL, ROLDAN). It is expected to contribute to new reflections with the discussions on the more adequate methodology for contemporary issues which arise in the areas of art and education. They are not and not intend to be conclusive, but that they intend to expand the dialogue, more specifically, for the Visual Arts teacher education, under multiple perspectives, and with the collaboration between students and teachers, researchers and participants in the development of this research.

\section{Keywords}

audiovisual; documentales; taller; video digital.

\section{Resumen}

Este trabajo presenta nuestras reflexiones y percepciones sobre los procesos de identidad y formación del profesor de Artes Visuales a través de ensayos fotográficos. Se inserta em el contexto de um proyecto de investigación que optó por la Investigación Educativa Basadaen Artes Visuales (IEBA) como referencia metodológica (HERNÁNDEZ, MARTINS, DIAS) y, em el caso de este artículo, se enfoca em las contribuciones de la fotografía como estratégia y instrumento de investigación cualitativa (VIADEL, ROLDAN). Se espera que contribuya a nuevas reflexiones com las discusiones sobre metodologías más apropriadas para los problemas contemporâneos que surgen em las áreas de arte y educacíon, que no son ni pretenden ser concluyentes, sino que pretenden ampliar el diálogo, más especificamente, a la formación del profesor de Artes Visuales, bajo múltiples perspectivas, y com lacolaboración entre estudiantes y docentes, investigadores y participantes em el desarrollo de esta investigación.

\section{Palabras-clave}

Investigación Educativa Basada en Artes Visuales; IEBA; Foto-ensayo; A/r/tografía; Formación de profesores.

ISSN: 2447-1267 
Este trabalho tem por objetivo compartilhar nosso percurso investigativo a respeito dos processos identitários e formativos do professor de artes visuais, trilhado no âmbito de um projeto de pesquisa ${ }^{1}$. O artigo apresenta uma parte de nossas reflexões e percepções a este respeito, que não são nem pretendem ser conclusivas, mas intentam ampliar o diálogo entre os pares. Optamos por fazê-lo por meio de foto-ensaios, considerando o extenso material visual produzido durante o processo.

Chegamos a uma região fronteiriça após um percurso que se iniciou pelo território das narrativas autobiográficas ou narrativas de formação (Cf. JOSSO; DOMINICÉ) e, a meio caminho, se encontrou no campo dos estudos sobre a Pesquisa Educacional Baseada em Artes (HERNÁNDEZ; DIAS) e sobre o uso da fotografia em contextos de pesquisa qualitativa (MARIN-VIADEL; ROLDAN). E a chegada a este novo território tem nos motivado cada vez mais a apostar no potencial das imagens, das visualidades e das estratégias criativas e criadoras para as nossas atividades de pesquisa e de formação. Nessa senda, a colaboração entre estudantes e professores e pesquisadores e participantes tem nos permitido olhar as coisas sob múltiplas perspectivas.

\section{Nos entre-lugares da pesquisa em/sobre arte e educação}

A Pesquisa Educacional Baseada em Artes (PEBA) tem se estabelecido no meio acadêmico, especialmente na última década, como uma alternativa às abordagens tradicionais de pesquisa, que tendem a negligenciar aspectos importantes para a investigação no campo das artes e da educação. Aspectos estes que podem ampliar nossa compreensão a respeito dos fenômenos e experiências humanas e alcançar determinados níveis de percepção que não podem ser alcançados pelos tradicionais métodos de pesquisa. $O$ desejo de objetividade, uniformização e impessoalidade de tais metodologias limita o campo da investigação, excluindo dados significativos, restringindo as estratégias e silenciando ou diminuindo a participação dos diversos sujeitos da pesquisa. Conforme Belidson Dias:

[...] estas novas formas de expressão acadêmica surgiram da inadequação dos discursos acadêmicos correntes em alcançar as especificidades na pesquisa em artes. Por meio de formas criativas, elas estabeleceram oportunidades de ver, experimentar o ordinário, aprender a compreender as novas e diferentes maneiras de se fazer pesquisa em artes, e deram especial atenção a forma da sua circulação e publicação. Os pesquisadores envolvidos em desconstruir a escrita acadêmica dominante (...) exploram modos criativos de representação

\footnotetext{
1 projeto de pesquisa intitulado "A formação do professor de artes visuais em uma perspectiva autobiográfica" insere-se no campo do ensino de arte, e tem por objetivo investigar os processos de formação, conhecimento e aprendizagem de professores de artes visuais, do ponto de vista de si mesmos, a partir das experiências consideradas por eles como formadoras, bem como a constituição de suas identidades docentes. Vem sendo desenvolvido no Departamento de Artes Visuais da Universidade Estadual de Londrina desde 2017. Optamos por uma abordagem qualitativa de pesquisa, de caráter biográfico, fundamentada principalmente nos trabalhos de Josso, Finger e Dominicé e Nóvoa sobre histórias de vida e narrativas autobiográficas e adotamos, como principais estratégias metodológicas, narrativas orais, verbais e visuais. Os resultados obtidos têm sido publicados em revistas especializadas e eventos científicos na área.
} 
que reflitam a riqueza e a complexidade das amostras e dados de pesquisa, promovendo múltiplosníveis de envolvimento, que são, simultaneamente, cognitivos e emocionais (DIAS, 2013, p. 4).

Dentre as muitas contribuições da PEBA aos estudos no campo da arte e da educação, destacamos algumas que foram fundamentais em nosso trabalho, tais como o fato de: levar em conta as particularidades e especificidades de cada caso vivenciado, experimentado e analisado; considerar a individualidade de cada participante; perceber as relações entre pesquisador e participante como uma troca contínua que, para ambos os lados, agrega conhecimentos e descobertas realizadas pela experiência; valorizar os processos de subjetivação; considerar e acolher maneiras criativas de colher dados e analisá-los de forma interpretativa e, principalmente, utilizar estratégias, recursos e procedimentos da própria arte ou inspirados nela (DIAS, 2013, HERNÁNDEZ, 2013).

A educação e a arte são práticas culturais que se servem de elementos subjetivos para dar ao homem referências básicas para a condução de sua existência. $\bigcirc$ caráter cultural e simbólico da prática educativa nos leva a questionar o modelo de formação que prioriza os aspectos técnicos e racionais. Os professores constroem seus saberes continuamente no decorrer de suas vidas, nem sempre de forma planejada e/ou consciente, o que justifica a necessidade de se levar em consideração a dimensão psíquica na análise dos processos de construção das identidades e na formação docente. São também o resultado de processos de identificação e diferenciação em relação a outrem, de tomadas de posição no convívio social e também movidas por desejos e necessidades, de forma que carregam consigo os traços das suas culturas, tradições e histórias particulares e, embora dependam e se alimentem de modelos educativos, não se deixam controlar por eles. Se na pós-modernidade colocamos em dúvida a existência de um eu único, um eu idêntico a si mesmo, e passamos a pensar em um sujeito errante, em contínua criação de si mesmo, sempre aberto à dúvida, interessa-nos mais investigar os modos como se inventa, como nos conta a sua própria estória e os sentidos que lhe dá, sem esquecer jamais que se trata sempre de uma narrativa.

Só assim se pode escapar, ainda que provisoriamente, à captura social da subjetividade, a essa captura que funciona nos obrigando a ler-nos e escrevermo-nos de uma maneira fixa, com um padrão estável. Só assim se pode escapar, ainda que seja por um momento, aos textos que nos modelam, ao perigo das palavras que, ainda que sejam verdadeiras, convertem-se em falsas uma vez que nos contentamos com elas (LARROSA, 2006, p. 40).

Daí a importância de o professor lançar-se à pesquisa sobre si mesmo, desconstruir suas verdades, reconfigurar seus conceitos e procurar descobrir qual o sentido de sua atuação. Desvelar a sua história e descobrir o que o faz ser o professor que é, observando as diferentes posturas que assume ou assumiu ao longo de sua trajetória.

Esse viés narrativo e interpretativo acabou por resgatar e ressignificar as narrativas biográficas e autobiográficas por sua capacidade de reconstrução da experiência 
vivida, valorizando a perspectiva pessoal e o papel dos participantes que atuam como coautores da pesquisa. $O$ investigador deixa de ser um observador distante e se envolve em todo o processo, não apenas como um coletor de dados ou ouvinte das narrativas, mas atuando junto com os participantes colaboradores. $O$ trabalho biográfico exige criatividade em todos os momentos da pesquisa, desde a escolha dos instrumentos de coleta de dados até a interpretação dos dados, que é também um processo de recriação e atribuição de sentidos (JOSSO, 2004).

Os aspectos subjetivos necessitam de especial atenção especialmente quando se trata da formação em arte, dado o seu caráter experiencial, que mobiliza e articula sentidos e emoções ao intelecto. Na procura por novas alternativas para a construção da pesquisa em Artes, a PEBA incorpora e vincula conceitos, objetos e procedimentos derivados das artes visuais a concepções e práticas da educação. Nesse contexto, os artefatos e procedimentos artísticos, bem como as imagens, físicas e mentais, são dados de pesquisa e estratégias metodológicas, podendo ser ainda a própria interpretação dos dados ou a sua apresentação. Como sintetiza Fernando Hernández:

Um tipo de pesquisa de orientação qualitativa que utiliza procedimentos artísticos (literários, visuais e performativos) para dar conta de práticas de experiências em que tantos os diferentes sujeitos (investigador, leitor, colaborador) como as interpretações sobre suas experiências desvelam aspectos que não se fazem visíveis em outros tipos de pesquisa (HERNÁNDEZ, 2017, p. 44).

Foi nessa perspectiva que se organizou nosso trabalho: realizado no âmbito de um grupo de estudos, pesquisa e formação, composto por professores da rede pública, estudantes e professores de Artes, em um processo de investigação coletivo e colaborativo. Compartilhamos experiências vividas em nossas trajetórias de vida pessoal e profissional que de alguma forma deixaram marcas formadoras e delineadoras de nossas identidades docentes. Objetivamos compreender o significado de nossas escolhas profissionais, processos formativos e do que fazemos na prática de ensino. A opção por essa metodologia e suas respectivas estratégias de coleta e interpretação de dados tem nos permitido criar espaços de compartilhamento de subjetividades por meio da experiência artística, que possibilitem a cada um rever e ressiginificar a própria formação. Permite ainda acessar determinadas dimensões da formação do professor, em constante e recíproca interação com a trajetória pessoal, e perceber o quanto ela está imbricada no processo de constituição de sua identidade. Trata-se de elaborações que se dão ao longo do tempo, razão pela qual nos parece mais apropriado falar de processos formativos do que falar de formação, assim como de processos identitários do que de identidade (HALL, 2006; HERNÁNDEZ, 2005; SANTOS, 1999).

As narrativas autobiográficas foram incorporadas aqui como estratégias da pesquisa e materializadas na forma de autorretratos e cartografias envolvendo desenho, pintura e bordado e culminando na produção de uma vestimenta autobiográfica. $\mathrm{Na}$ confluência desses territórios e campos de saber, ampliaram-se as nossas perspectivas e olhares para os objetos de nossa investigação. 


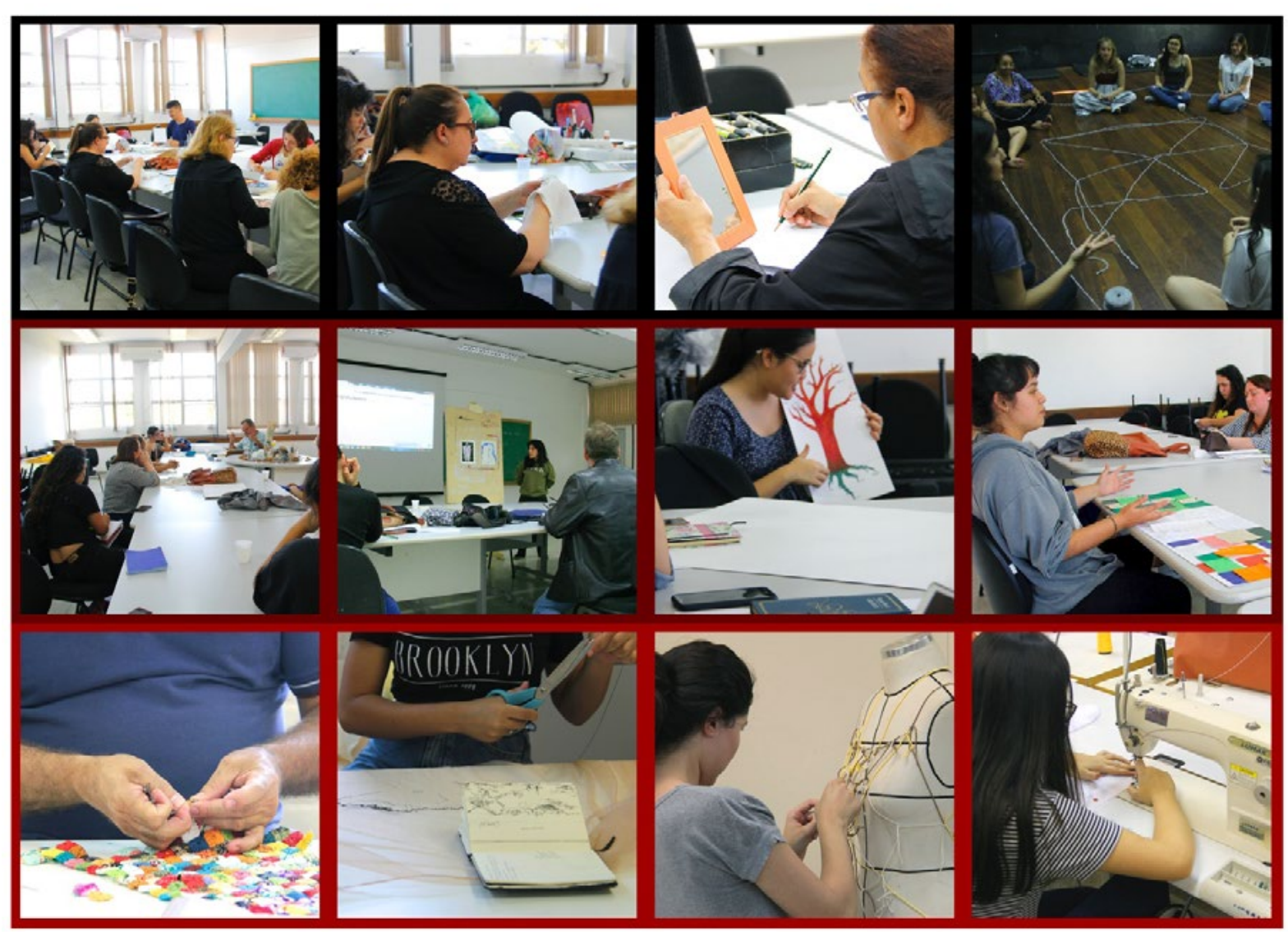

Desenvolvimento dos primeiros encontros - produção poética: Confecção de autorretratos, cartografias e Oficinas.

Momentos de compartilhamento: experiências e reflexões acerca da produção poética das cartografias.

Criação de vestimentas cartográficas e produção

Fig.1. Autores, 2019. Resumo visual composto por doze fotografias digitais do percurso da pesquisa.

\section{A fotografia como estratégia de pesquisa em arte e educação}

O caráter colaborativo, relacional e multidisciplinar da PEBA deriva de sua natureza rizomática ${ }^{2}$. Nesse espaço fronteiriço, estamos constantemente fazendo conexões: entre diferentes campos de conhecimento, entre teoria e prática, entre pesquisadores e colaboradores, entre estudantes e professores, entre arte e educação. No trabalho que realizamos, a arte permitiu criar visualidades para as narrativas de formação, inclusive durante o próprio processo de rememoração das experiências vividas, funcionando como pensamento visual e não somente como representação. Muitas vezes elas revelam nuances e sutilezas das quais o próprio participante não tinha consciência até aquele momento.

Trabalhar com imagens é articular idas e vindas no tempo, inventando mundos e narrando histórias. É escolher e organizar fluxos imagéticos que

\footnotetext{
${ }^{2}$ Conforme conceito desenvolvido por Gilles Deleuze e Felix Guattari e aqui referindo-se à possibilidade de se estabelecer múltiplas conexões entre diferentes áreas do conhecimento, entre os diferentes atores da pesquisa, entre diferentes estratégias e encaminhamentos metodológicos (DELEUZE; GUATTARI,1995).
} 
se espalham no tempo, realidades múltiplas que se constroem, ficções que se tornam realidades. Ao pensar com imagens, buscamos possibilidades de promover outros espaços e ideias, extraindo dos fluxos do tempo oportunidades de ensinar, aprender, socializar, politizar, educar e criticar nos contrapondo a homogeneidades históricas, artísticas e educacionais. Graças às temporalidades, construímos, recuperamos, revisamos, disputamos, atualizamos e renovamos sentidos e significados (MARTINS, p. 85).

Ao longo do percurso, cada um dos participantes produziu um autorretrato, uma cartografia da formação e uma vestimenta autobiográfica, apresentados ao grupo por meio de narrativas orais e registradas em áudio. Procuramos estimular os participantes a pensar e a expressar-se por meio de imagens. Elas estiveram presentes em todos os momentos e de diversas formas. Além da produção mencionada, foram trazidas fotografias do acervo pessoal, objetos familiares trazidos de casa e trabalhos de artistas. As próprias lembranças suscitadas no processo de rememoração se dão por meio de imagens mentais.

O conjunto dos objetos trazidos e/ou produzidos, bem como todo o conjunto das atividades, foi fotografado, e é justamente sobre esse conjunto de imagens que incide o foco deste trabalho. Desde o início, cada um dos participantes foi convidado a fotografar o processo, com o objetivo de estimular olhares particularizados, diferentes perspectivas e registros poéticos. Pensar em uma apresentação dos resultados e do percurso da nossa pesquisa por meio de imagens fotográficas foi, portanto, uma escolha quase natural.

Um aspecto característico da Metodologia Artística de Pesquisa baseada na Fotografia é a forma como as imagens descrevem, analisam e geram situações que podem ser vistas por outros ângulos, propondo novos modelos de visualização da complexidade do conjunto da cultura material e/ou de um problema educacional (EGAS, 2015, p. 3437).
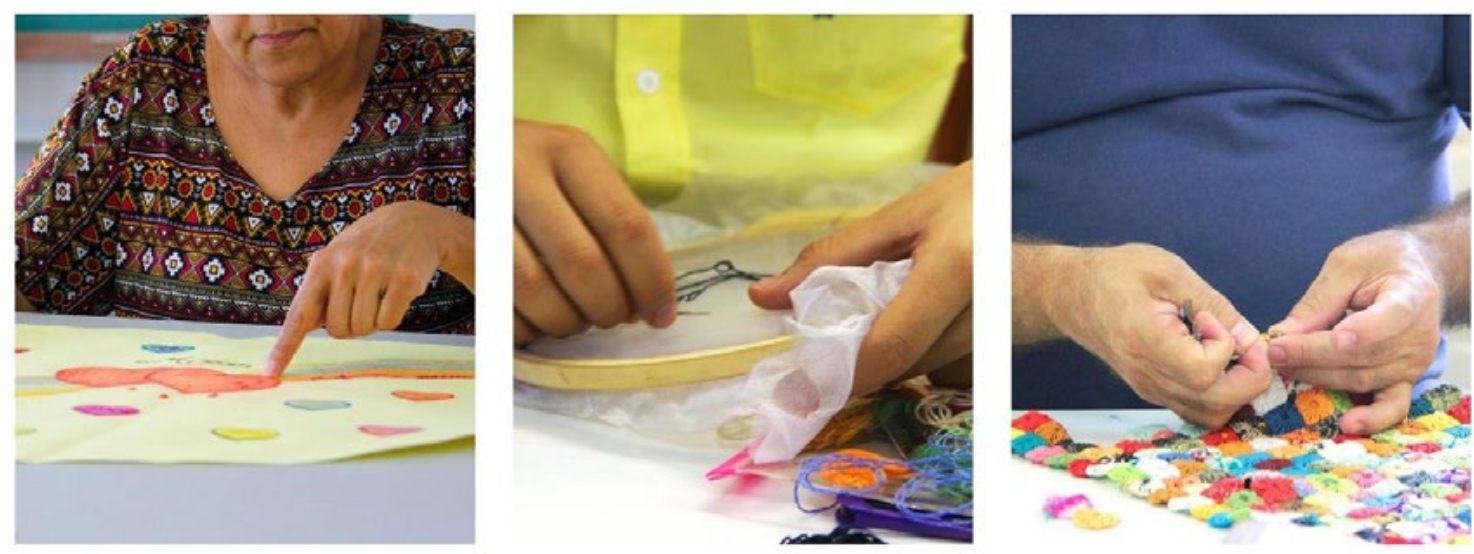

Fig.2. Autores. Percursos das mãos. 2019. Resumo visual composto por três fotografias digitais da elaboração de produções poéticas do projeto de pesquisa. 
Para Ricardo Marin-Viadel e Joaquin Roldán (apud EGAS, 2015), recorre-se à fotografia por meio de dois usos metodológicos: extrínseco - imagem como dado; e o intrínseco - imagem como pensamento visual, de forma a proporcionar ao pesquisador e ao observador dados despercebidos, novas narrativas e questionamentos, tornando o ordinário em extraordinário. A primeira forma de uso é bastante comum e utilizada há muito tempo em pesquisas; já a segunda, é relativamente recente, se dá, principalmente, no contexto das pesquisas de caráter qualitativo e requer o cuidado de não as tornar novamente imagens meramente ilustrativas dos processos de investigação. São imagens que falam por si, sem a necessidade de explicações ou de traduções, dado que, muitas vezes, dá conta do que o texto não foi capaz de fazer ou porque o faz com uma riqueza maior, no sentido de permitir novas compreensões, percepções e conexões.

Os autores sugerem algumas modalidades de uso ou estruturas visuais, tais como a fotografia independente, as séries fotográficas, as foto-colagens e os foto-ensaios. Optamos por trabalhar com a última, por sua capacidade de sintetizar um processo tão rico em imagens e que dificilmente seria descrito textualmente. De acordo com os autores:

Cada uma das fotografias que configuram um foto-ensaio e, sobretudo, as interrelações que estabelecem umas imagens com as outras, compõem sucessivas possibilidades de interpretações e significados até dar forma, com suficiente clareza, a uma ideia ou um raciocínio. Os Fotos-Ensaios podem ser acompanhados de texto escrito, e de fato, na maioria dos casos são publicados assim, mas a contribuição fundamental para a pesquisa é notadamente visual [...] Os fotos-ensaios servem, principalmente para expor uma argumentação visual porque exploram, ao máximo, as possibilidades narrativas e demonstrativas das imagens e não somente suas funções figurativas ou representacionais (MARIN-VIADEL, ROLDAN apud EGAS, 2015).

Mais adiante, complementam que: "O Foto-Ensaio Interpretativo consiste na resposta visual dos resultados da pesquisa" (EGAS, 2017, p. 205), ajustando o alinhamento com os nossos objetivos. Analisar os dados obtidos em um trabalho como este vai além de tabular e categorizar, uma vez que eles não são apenas coletados mas produzidos durante seu desenvolvimento, de modo que não é possível saber previamente o que será produzido pelo grupo.

Para o desenvolvimento deste artigo, apresentamos quatro foto-ensaios elaborados por nós como narrativas visuais de percursos e processos criativos individuais de quatro participantes, a partir das fotografias produzidas pelo grupo. Eles seguem uma organização semelhante entre si, no sentido de trazer os diferentes momentos do trabalho: a apresentação de objetos trazidos de casa; a produção poética de um autorretrato, uma cartografia, e vestimenta autobiográfica; os momentos de compartilhamento com o grupo por meio das narrativas orais.

Individualmente, oferecem ainda um panorama das temáticas surgidas no decorrer do processo de rememoração das experiências reconhecidas por eles como formadoras. Referem-se às primeiras experiências com a arte, às diferentes matrizes e referências culturais familiares, aos diversos contextos educativos desde os primeiros 
anos da escolaridade até a graduação ou pós, aos professores ou profissionais com quem se teve contato, às motivações para escolha e permanência na profissão, às aprendizagens adquiridas na prática docente e na interação com os colegas de trabalho e com os seus alunos, aos espaços de pertencimento e às paisagens cotidianas. Revelam um universo de miniprocessos em constante desenvolvimento e interação, resultando na densa trama que chamamos de formação.

Mas é fundamental que se reconheça sempre que as narrativas de formação são tão singulares quanto são as histórias de vida de cada pessoa, já que a formação é muito mais ampla e complexa do que normalmente nos damos conta e está intimamente relacionada aos processos identitários (DOMINICÉ, 2010).

\section{Descobrindo caminhos, reconfigurando rotas: foto-ensaios de trajetórias docentes}
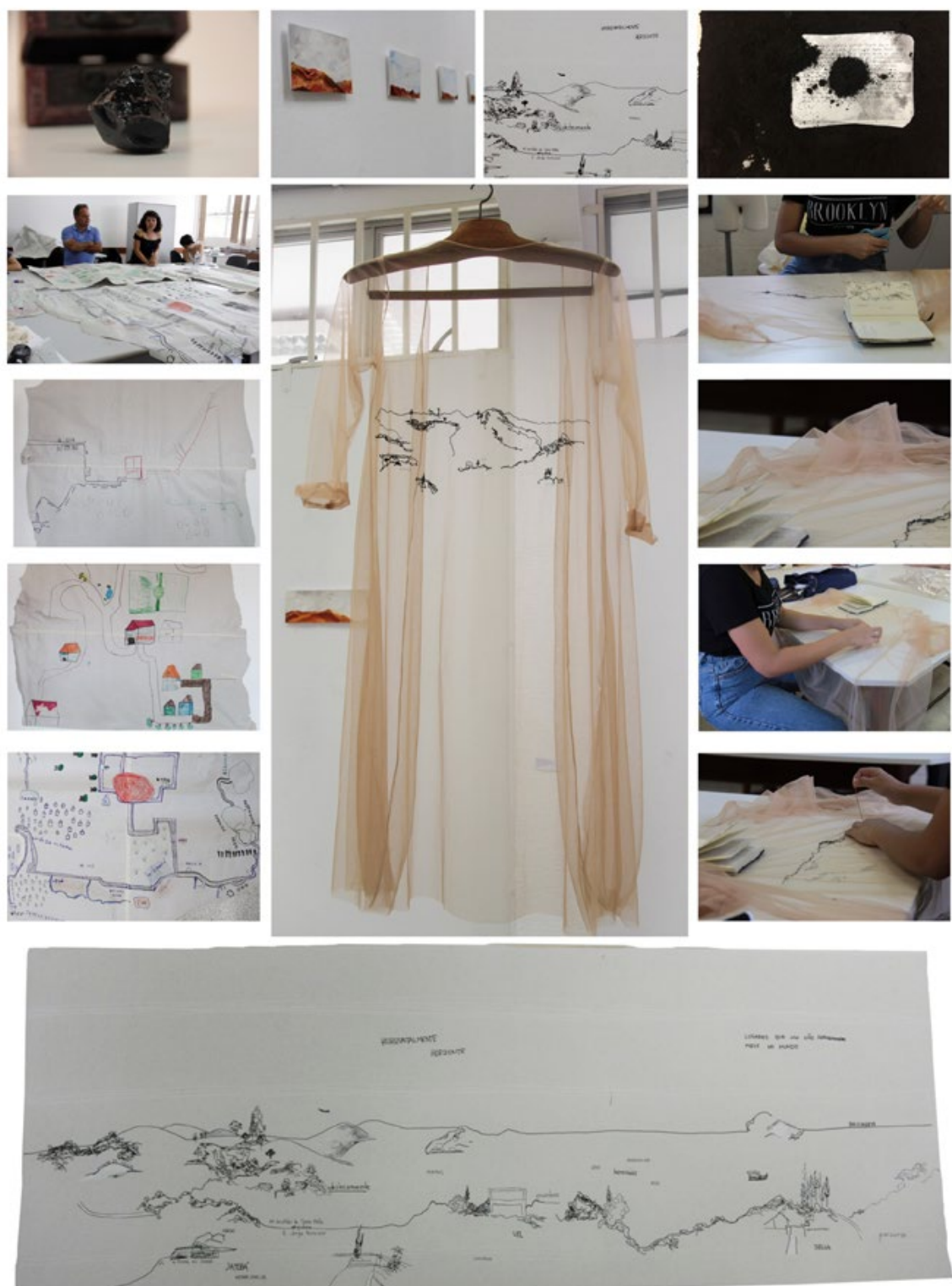

Fig.3. Autores. Foto-ensaio. Narrativas visuais da trajetória de formação de TH. 2018 - 2019. 

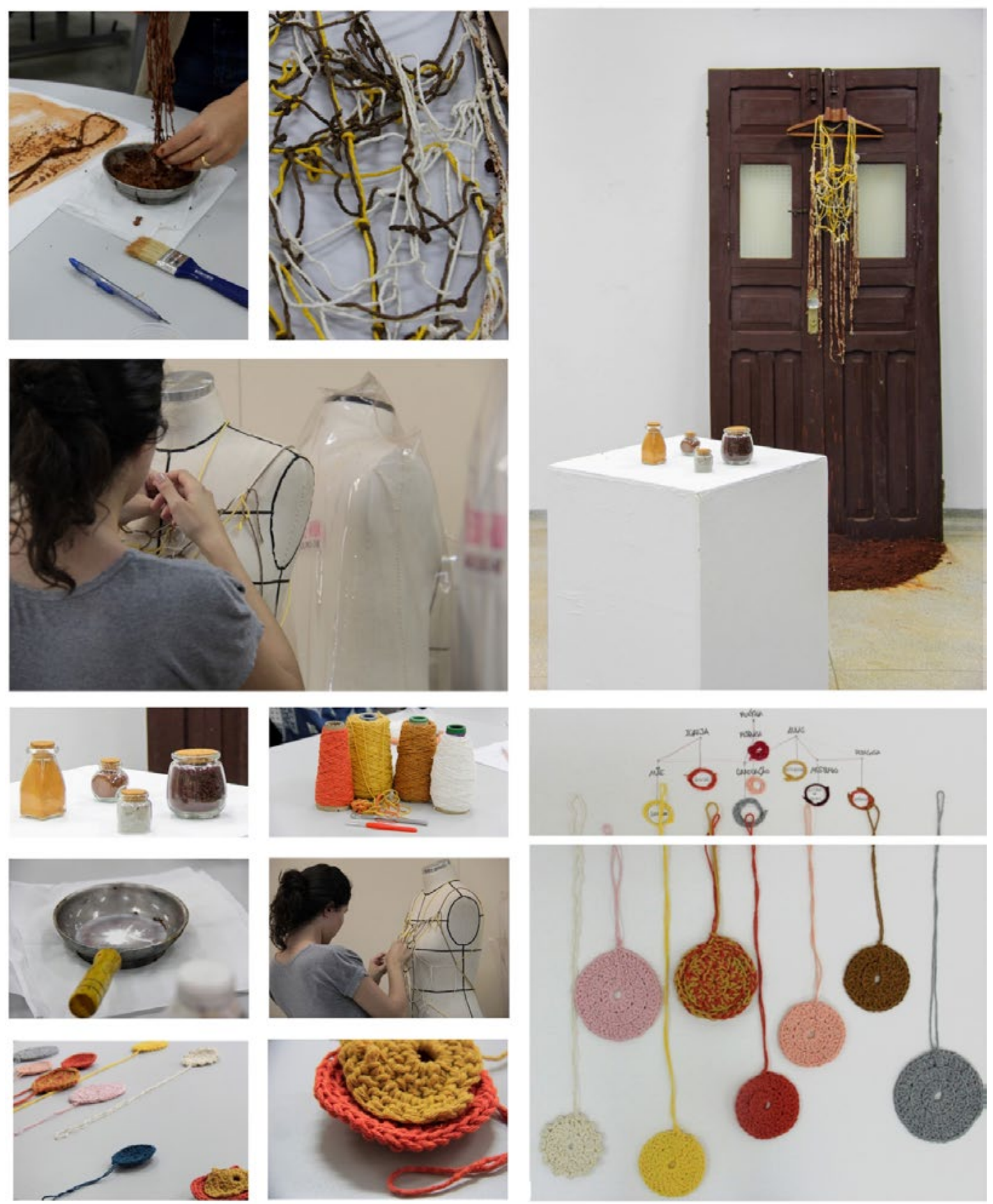

Fig.4. Autores. Foto-ensaio. Narrativas visuais da trajetória de formação de DE. 2018 - 2019. 

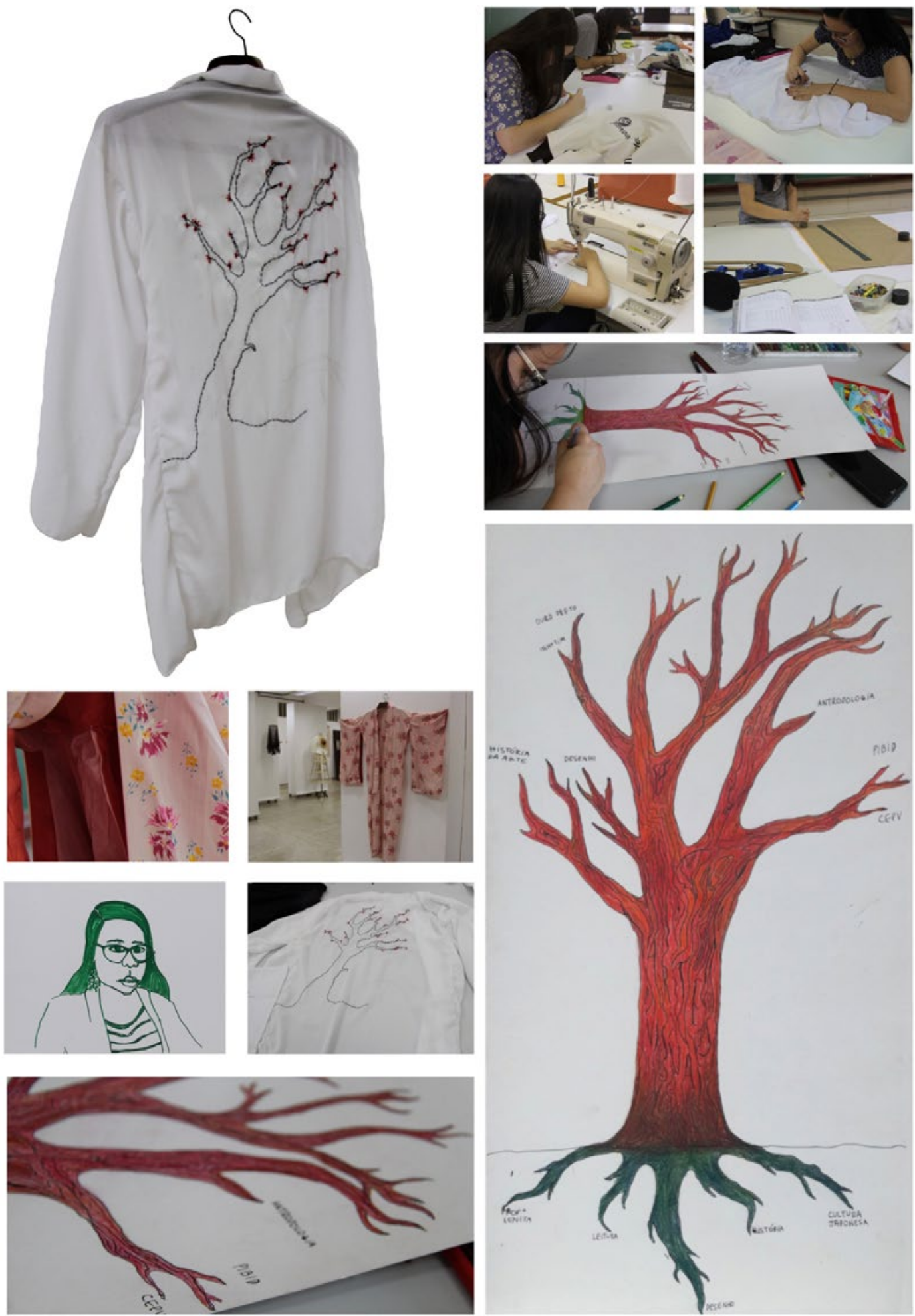

Fig.5. Autores. Foto-ensaio. Narrativas visuais da trajetória de formação de VI. 2018 - 2019. 

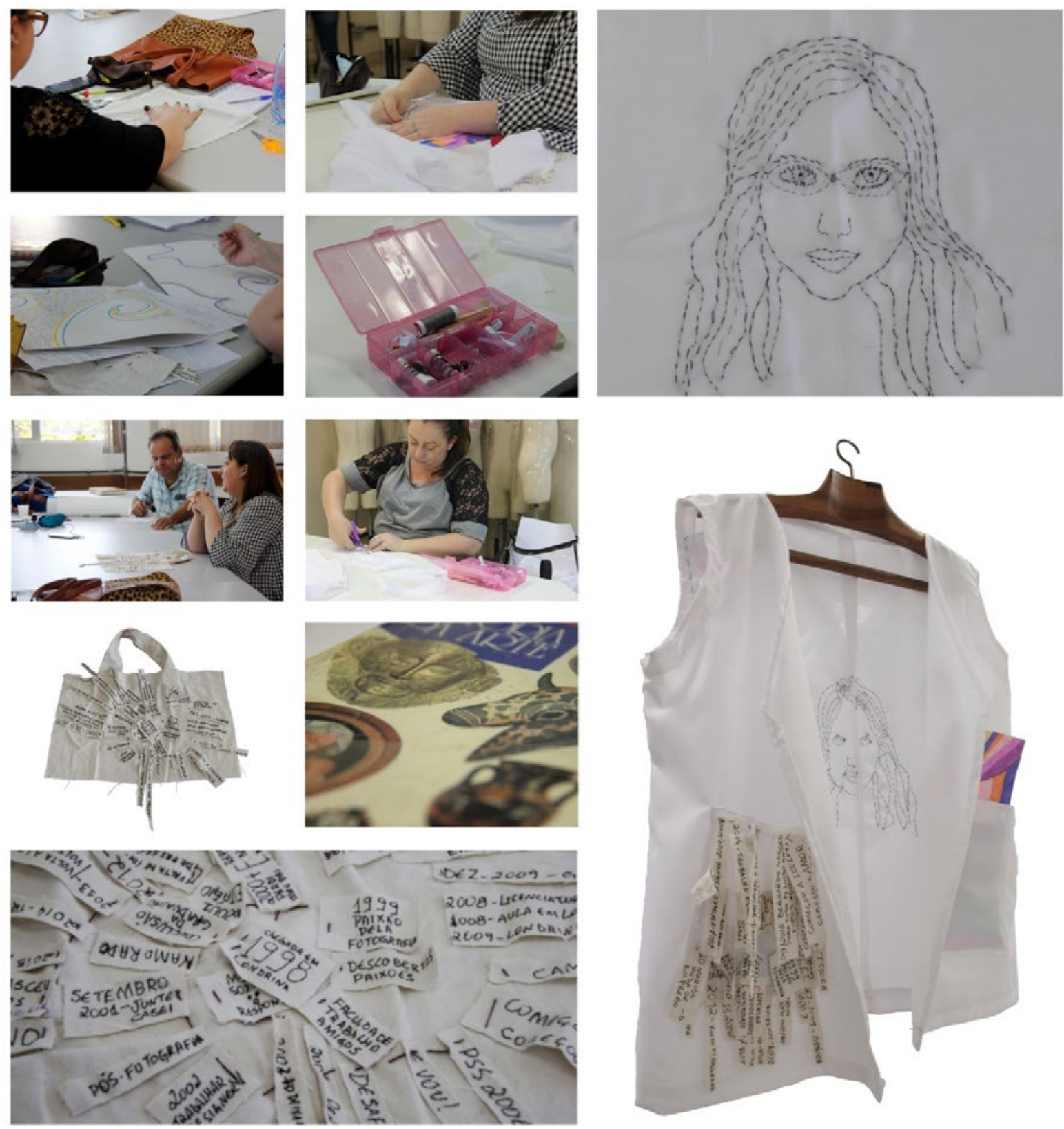

Fig.6. Autores. Foto-ensaio. Narrativas visuais da trajetória de formação de TA. 2018 - 2019.

\section{A pesquisa e a formação permeadas pela experiência estética e/ou artística}

O exercício de olhar para si e de ouvir o outro, de rever sua trajetória de formação e ajustar o rumo, assumindo a autoria de sua própria história, necessita deum ambiente propício, de confiança e de partilha. Isso se dá em um processo dinâmico, em que muitas experiências e conhecimentos são compartilhados ao mesmo tempo em que são produzidos. O que vai muito além de coletar dados, observar, sistematizar e categorizar. Aqui os dados são produzidos e todo o processo é permeado por 
insights, tomadas de consciência, novas percepções e entendimentos que afetam a todos ou a cada um dos participantes em diferentes momentos, deslocando-nos de nossos lugares e papéis. A possibilidade de rever e reconfigurar nossas histórias de vida nos leva a uma compreensão maior de nossos processos de formação, levandonos consequentemente, a uma maior autonomia em relação a eles. $O$ conhecimento é construído e compartilhado entre todos e não apenas para uma comunidade acadêmica e a posteriori. Quanto mais seguimos nesse caminho, mais percebemos a necessidade de pensar a pesquisa como formação e a formação como pesquisa, considerando a íntima relação entre uma e outra.

Outro aspecto importante a ser salientado nesse contexto da PEBA, é que, ao nos aproximarmos ou reaproximarmos dos fazeres artísticas ou criativas durante o próprio processo de investigar a formação, repensamos também nossas práticas pedagógicas e atuação docente. De acordo com Rita Irwin: "Problemas de pesquisa estão imersos nas práticas de artistas, educadores ou artista-educadores e, portanto, têm o potencial de influenciar essas práticas no e durante o seu tempo" (IRWIN, 2013, p. 29). A elaboração de autorretratos, cartografias e da vestimenta autobiográfica faz parte do conjunto de estratégias elaboradas para este trabalho, com a finalidade de oportunizar essa reaproximação dos participantes com tais processos, ao mesmo tempo em que nos permite analisá-los enquanto estão em curso.

As imagens estiverem presentes em diversos momentos e com diferentes objetivos: como gatilhos disparadores de memória, como objetos portadores de afetos, como registros de processo e como forma de apresentação dos resultados. A produção de imagens fotográficas para fins de registro foi proposta desde o início em uma perspectiva poética, de liberdade e abertura a olhares particulares sobre as experiências vividas em um espaço de compartilhamento, de escuta de si e do outro. Parte delas registra cada um dos artefatos produzidos ou trazidos para o grupo e outra parte nos convida ao deslocamento, a criar novos significados e outras narrativas.

Pensar sobre a apresentação dos resultados e do percurso da nossa investigação em formato de foto-ensaios foi, portanto, uma escolha quase natural, mas, ao mesmo tempo, desafiadora. Eles compõem uma cartografia de nossa trajetória enquanto grupo de investigação e, concomitantemente, de trajetórias particulares de formação e constituição de identidades docentes. Foram concebidos como apresentação parcial dos resultados de nossas investigações, abertos a múltiplas interpretações e novas interrogações.

\section{Referências}

DELEUZE, Gilles; GUATTARI, Félix. Mil platôs - capitalismo e esquizofrenia, v. 1. Tradução: Aurélio Guerra Neto e Célia Pinto Costa. Rio de Janeiro: Ed. 34, 1995.

DOMINICÉ, Pierre. O que a vida lhes ensinou. In: NÓVOA, António; FINGER, Matthias (Orgs.). O método (auto)biográfico e a formação. Natal, RN: EDUFRN; São Paulo: Paulus, 2010. p. 189-222. 
EGAS, Olga Maria Botelho. Metodologia artística de pesquisa baseada em fotografia: a potência das imagens fotográficas na pesquisa em educação. In: ENCONTRO DA ASSOCIAÇÃO NACIONAL DE PESQUISADORES EM ARTES PLÁSTICAS, 24., 2015, Santa Maria.Anais[...]. Santa Maria: ANPAP, 2015. p. 3434-3449.Disponível em:http://anpap.org.br/ anais/2015/simposios/s8/olga_egas.pdf. Acesso em: 6 jun. 2020.

As Metodologias Artísticas de Pesquisa em Educação e Deslocamentos na Formação Docente: a Fotografia como construção de um pensamento visual. 2017. 293 f. Tese. Universidade Prebisteriana Mackenzie. São Paulo. Disponível em http://tede.mackenzie. br/jspui/bitstream/tede/3264/5/Olga\%20Maria\%20Botelho\%20Egas .pdf. Acesso em: 6 jun. 2020.

HALL, Stuart. A identidade cultural na pós-modernidade. Rio de Janeiro: DP\&A, 2006.

HERNÁNDEZ, Fernando. A pesquisa baseada nas artes: propostas para repensar a pesquisa educativa. In: DIAS, Belidson; IRWIN, Rita (org.). Pesquisa educacional baseada em arte: a/r/tografia. Santa Maria: UFSM, 2013. p. 39-62.

A construção da subjetividade docente como base para uma proposta de formação inicial de professores de artes visuais. In: OLIVEIRA, Marilda Oliveira de; HERNÁNDEZ, Fernando (Org.). A formação do professor e o ensino das artes visuais. Santa Maria: Ed. UFSM, 2005. p.21-42.

IRWIN, L. Rita. A/r/tografia. In: DIAS, Belidson; IRWIN, Rita (org.). Pesquisa educacional baseada em arte: a/r/tografia. Santa Maria: UFSM, 2013. p. 27 -35.

JOSSO, Marie-Christine. Experiências de vida e formação. São Paulo: Cortez, 2004.

LARROSA, Jorge. Pedagogia profana: danças, piruetas e mascaradas. Tradução de Alfredo Veiga-Neto. Belo Horizonte: Autêntica, 2006.

MARIN-VIADEL, Ricardo. Las teorías educativas también se hacen com imágenes: pesquisa baseada em artes visuais. In: MARTINS, Mirian Celeste; BONCl, Estela; MOMOLI, Daniel (org.). Formação de educadores: modos de pensar e provocar encontros com a arte e mediação cultural. São Paulo: Terracota Editora, 2018. p. 131-144.

MARIN-VIADEL, Ricardo; ROLDÁN, Joaquín. Metodologías artísticas de investigación em educación. Málaga: EdicionesAljibe, 2012.

MARTINS, Raimundo. Metodologias visuais. In: DIAS, Belidson; IRWIN, Rita L. (org.). Pesquisa educacional baseada em arte: a/r/tografia. Santa Maria: UFSM, 2013. p. 83-95.

SANTOS, Boaventura de Sousa. Pela mão de Alice: o social e o político na pós-modernidade. Porto: Afrontamento, 1999.

Recebido em 13 de junho de 2020.

Aprovado em 06 de julho de 2020. 